\title{
An Assessment of Rural Poverty and Food Insecurity in Fika Local Government Area, Yobe State, Nigeria
}

\author{
Suleiman Kawuwa ${ }^{1 *}$, Umar Lawal Yusuf ${ }^{2}$ \\ ${ }^{1}$ Department of Sociology, Yobe State University Damaturu, Nigeria \\ ${ }^{2}$ Department of Sociology and Anthropology, University of Maiduguri
}

*Corresponding Author: Suleiman Kawuwa, Department of Sociology, Yobe State University Damaturu, Nigeria

\begin{abstract}
This study is an assessment of rural poverty and food insecurity in Fika Local Government Area, Yobe State. Poverty in Fika is overwhelmingly an endemic rural problem. Farming is the mainstay of the economy of this area. Unfortunately, majority of the people lack access to modern farming inputs, as such they are unable to produce what is sufficient to sustain them. As a result of this, poverty becomes very pervasive which in turn reinforce the level of food insecurity in the area. The main objective of the study is to assess rural poverty and food insecurity in Fika Local Government Area of Yobe State. The specific objectives are: to find out the factors associated with persistent poverty; to investigate the reasons for food insecurity; and to establish the degree to which rural farmers sell their food and other agricultural commodities immediately after harvest in Fika Local Government Area. A sample of 300 heads of households was taken using a multi- stage cluster sampling technique. Key informant interviews were also conducted with 10 stakeholders in the LGA. Interview schedule were used to collect data from the respondents and analysis was done using SPSS. Vicious cycle theory of poverty was used as the theoretical framework. The study found that most of the rural dwellers in Fika LGA are farmers but cannot produce sufficient food to cater for their needs throughout the year. The reasons for both poverty and food insecurity in Fika LGA, as found in the study, include illiteracy, unemployment, poor infrastructure, inability of some farmers to cultivate large farm land, rural - urban migration, shortage of farm inputs such as fertilizers, lack of rural extension officers, and poor storage facilities among others. Based on the findings of the study, some of the recommendations made: the farmers in the LGA should diversify their farm production to include cash crop; agricultural extension officers should educate the people on modern farming and storage techniques to boost their production capacity and to enable them preserve their excess productions. Government should put more efforts in reducing illiteracy and unemployment and also provide basic infrastructure in the areas. It should also come up with relevant Policies aimed at empowering the rural populace in the LGA.
\end{abstract}

\section{BACKGROUND TO THE STUDY}

Poverty and food insecurity is a global phenomenon, which affects continents, nations and peoples differently. It afflicts people in various depths and levels, at different times and phases of existence. There is no nation that is absolutely free from poverty. The main difference is the intensity and prevalence of this malaise. Consequently, poverty is a plague afflicting people all over the world. It is considered one of the symptoms or manifestations of underdevelopment (CBN/World Bank, 1999). Poverty is a vicious cycle that keeps the poor in a state of destitution and utter disillusionment and deprivation. Poverty is the main cause of hunger and malnutrition, which are aggravated by rapid population growth, policy inadequacies and inconsistencies or weak administrative capabilities, unhealthy food storage and processing techniques (Sanni, 2000). The world's poor are concentrated in 65 low income countries, mainly in South Asia and Sub-Saharan Africa, with a population of 3.2 billion and having a per capita income of $\$ 390$ per year (Patel, 1994). The concept of poverty reflects numerous visible attributes of multi- dimensional nature. Attributes of poverty may be classified into structural, economic, social, cultural and political deprivations.

Poverty is a phenomenon which so many individual would want to be far away from it. Unfortunately, the proximity of an individual or society to the phenomenon of poverty is not a matter of choice but a matter of the socio-economic, environmental and structural position an individual or society operates from. The phenomenon of poverty has economic dimension which revolve around the nature and level 
An Assessment of Rural Poverty and Food Insecurity in Fika Local Government Area, Yobe State, Nigeria

of material deprivation that afflict the poor and distinguishes them from the non-poor. This deprivation can be seen in terms of low income or low consumption, lack of basic physical necessities of life, lack of assets and other things like that.

Poverty produces in the life of an individual or society, social inferiority tag, lack of self-esteem, insecurity especially in food and life, vulnerability and marginalization. Poverty equally manifests in the nutritional habit of the individual. However, although the phenomenon of poverty exists in both rural and urban areas, its features manifest more among the rural dwellers as reflected in their low socio-economic setting. In other words, the alarming features and consequences of poverty thrive more among the rural people. As Olaiyide and Olajuwan (1981) posit:

In terms of working capital and scale of operations, poverty is expressed in poor and crude tools, smallness of the scale of operations, poor output that is incapable of meeting the needs of the family.

This perhaps is one of the major reasons why poverty is mostly associated with the rural dwellers as soon as it is mentioned, to the extent that individual going to the city are tagged to be in search of brighter fortune or will be living in good life like having access to major essentials of life such as portable drinking water, electricity, education, good road among other things. Since poverty has a correlation with the nature of food intake, it therefore, follows that rural poverty will affect food security and its ways.

The rural area stands as the root of agricultural produce and yet cannot command food security for a year. The major focus of development is pitched mainly on urban centres against the plight of rural communities that are the root of national food (New Nigeria News Paper, March 7, 1990). The rural community as root of agricultural produce is expected to have a guaranteed food security. Unfortunately, those who produce food are the most food insecure.

Fika Local Government Area, Yobe State contains many rural areas, thus, their inhabitants are suffering much from the poverty syndrome, which further manifest in their incapability to ensure food security in their area. Since the rural dwellers are mostly poor and their major source of livelihood is farming, the only way they can afford some of the basic necessities of life is for them to sell off their farm produce at farm gate price which renders them food unsecure. In addition, these farmers sell out their produce cheaply and, in turn, buy other necessities of life at a very high price, further rendering them not only food deprived but also trapped in a vicious cycle of poverty. These processes make poverty and food insecurity to operate in a vicious cycle.

Although food security is defined in various ways, the World Food Summit of 1996 defined food security as existing "when all people at all times have access to sufficient, safe nutritious food to maintain a healthy and active life". The idea of food security was presented for the first time at the world food conference in 1974 viewed solely from the perspective of having adequate availability of food on a national scale. Today, it is a condition in which all people have access at all times to enough food of an adequate nutritional quality for a healthy and active life (World Bank, 1986 as cited in Adebayo, 2010). Food security, according to Tollence (2000), has four dimensions. These include:

- Availability of sufficient amount of food which is a function of food production.

- Stability of supply over time which depends on the ability to preserve/store produce food and supplement available food through imports if necessary.

- Access to the available food which depends on income levels and its distribution.

- Food utilization which encompasses procurement, ingestion and digestion all of which are dependent on nutritional quality, education and health

\subsection{Statement of the Research Problem}

Poverty in Fika is overwhelmingly an endemic rural problem. The main occupation of the rural people of Fika is farming and they operate a subsistence mode of production, that is, a production that meets only the need of the family. Another most common challenges are the issue of production capability where very few were able to cultivate large farm because of low income and poverty, poor access to production inputs, such as modern farming implement, fertilizer, insecticides, tractors, and improved 
An Assessment of Rural Poverty and Food Insecurity in Fika Local Government Area, Yobe State, Nigeria

seeds and seedlings. As a result of these, majority could not produce sufficient amount of food and other crops for the sustenance of their families, and even if they produce sufficient amount of food and other crops for the family, social and economic factors compel many of them to sell sizeable amount of the available produce at a time when it was cheaper. This cause the family to run short of food supply before the next cropping season. In Fika rural areas it is also very common to see the rural poor working as hired labourers in order to earn some income for the daily supply of food to the family during the cultivation season, leaving their farm uncultivated, which consequently leads them to low harvest. This situation eventually causes serious shortage of food in terms of availability, access and stability. This is especially acute during the farming season in which food intake is most required in order to engage in the arduous work of tiling the land.

This study, therefore, assesses the extent of rural poverty and food insecurity in Fika Local Government, Yobe State, Nigeria. In view of the above, the study attempts to answer the following research questions:

- What are the causes of poverty among rural dwellers in Fika Local Government Area?

- What are the reasons for food insecurity among the rural people of Fika Local Government Area?

- To what extent do rural dwellers sell their farm produce immediately after harvest to meet other needs?

\subsection{Aim and Objectives of the Study}

The main objective of the study is to assess rural poverty and food insecurity in Fika Local Government Area of Yobe State. The specific objectives of the study include:

- To find out the factors associated with persistent poverty among rural dwellers in Fika Local Government Area.

- To investigate the reasons for food insecurity among rural dwellers in Fika Local Government Area.

- To establish the degree to which rural farmers sell their food and other agricultural commodities immediately after harvest in Fika Local Government Area

\section{REVIEW OF LITERATURE}

\subsection{Meaning of Poverty}

Based on its multi-dimensional nature, poverty is usually perceived using different criteria. This accounts for the numerous attempts in defining poverty; each definition tries to capture the perception of the author or the poor as to what the term is. Narayan and Petesch (2002:10) succinctly posit that, "poverty also may look quite different, seen through the eyes of a poor man or a woman." This is reflected in the differences in the various definitions, as poverty is considered to be a relative term. Narayan et al (2000:30) captured the definition from the point of view of the poor in different countries in the following perspectives: "Poverty is humiliation, the sense of being dependent and of being forced to accept rudeness, insults, and indifference when we seek help." Another of such views of the poor is that expressed by a poor man in Kenya in 1997 as reported by Narayan et al (2000:30) thus:

Don't ask me what poverty is because you have met it outside my house. Look at the house and count the number of holes. Look at my utensils and the clothes that I am wearing. Look at everything and write what you see. What you see is poverty.

The above reflect just descriptions of a few of the various perceptions of Poverty at least from the poor. Poverty could denote a state of deprivation as was captured by Organization for Economic Cooperation and Development (OECD,1992:3) as process. It could also denote:

... absence or lack of basic necessities not having enough to eat, a high rate of infant mortality, a low life expectancy, low educational opportunities, poor water, inadequate health care, unfit housing and a lack of active participation in the decision making of life" or "lack of command over basic consumption needs such as food, clothing and shelter, or glaring defects in the economy, etc" as stated by Aluko1975 (cited in Oyemomi, 2003). 
An Assessment of Rural Poverty and Food Insecurity in Fika Local Government Area, Yobe State, Nigeria

The attempts made at defining poverty as captured above could be referred to as mere outline of the features or characteristics of poverty. In buttressing the difficulties encountered in arriving at a common and generally accepted definition of poverty, Aboyade (1997) posits that there seems to be a general agreement that poverty is a difficult concept to handle, and that it is more easily recognized than defined. Even attempts made to categorize some specific areas at which poverty could be viewed are loaded with lack of agreement. For instance, the OECD Guideline on Poverty Reduction (2000:29) stressed that:

An adequate concept of poverty should include all the most important areas in which people of either gender are deprived and perceived as incapacitated in different societies and local context. It should encompass the causal links between the core dimensions of poverty and the central importance of gender and environmentally sustainable development."

Though OECD failed to define poverty, it has succeeded in getting the core dimensions in the definition of poverty which should cover or include: economic, human, political, socio-cultural and protective capabilities. On the other hand, Narayan et al (2000: 29-30), in buttressing that poverty is multi- dimensional, argued that "definitions of poverty and its causes vary by gender, age, culture, and other social and economic contexts." They defined poverty from such categories as: lack of voice, power, independence, well or ill being, regional, gender, etc. Even poverty elements like lack of power and voice, are explained differently in various countries. A Ghanaian in 1995 as stated in Narayan et al (2000:39) explained poverty in the dimension of lack of power and voice thus, "you know good but you cannot do 'good'. That is, such a person knows what should be done but has not got the means." In the same vein, an elderly poor man in Uganda explained in his own words;

The forces of poverty and impoverishment are so powerful today. Governments or the big churches can only manage them. So we now feel somewhat helpless. It is the feeling of helplessness that is so painful, more painful than poverty itself.

Adopting categorization as a basis for defining poverty generates even more disagreements as to what constitutes poverty at different levels of society such as the individual, household, community, district and regional. OECD (2000:33) states that dimensions and measures of poverty may be inconsistent, which complicates the task of identifying the poor. Lending credence to the divergent views on poverty definition, the World Bank states that:

Participatory studies have cumulatively shown that the poor also experience and understand their poverty in terms of a range of non-material and intangible qualities such as insecurity, lack of dignity and status or a lack of power or opportunity (World Bank, 1999: 10).

These qualities and characteristics of poverty differ markedly by social group and by geographical and political economic contexts. Furthermore, examining the definition of poverty from the dimension of material wellbeing reveals yet other varying opinions. The case of a 10-year old child in Gabon in 1997 as reported by Narayan et al (2000:39) succinctly captures it thus: "when I leave for school in the mornings I don't have any breakfast. At noon there is no lunch, in the evening I get a little supper, and that is not enough. So, when I see another child eating, I watch him, and if he doesn't give me something I think I'm going to die of hunger." Material wellbeing is always relative. While some perceive it in terms of ability to meet basic needs such as the provision of three square meals daily, as in the cases above, few perceive it from ability to educate one's children, provide clothing for the family and live in a relatively comfortable shelter; yet, some perceive it from ability to respond to emergencies by falling back on ones' savings. The lack of these things is ordinarily perceived as illbeing and by extension, poverty.

According to OECD (2000:30) "economic capability means the ability to earn an income, to consume and to have assets, which are all keys to food security, material well-being and social status. These aspects are often raised by poor people, along with secure access to productive financial and physical resources: land, implements and animals, forests and fishing waters, credit and decent employment".

Expressing poverty from the gender dimensions, the OECD (2000:32) further observes that:

The processes causing poverty affect men and women in different ways and degrees. Female poverty is more prevalent and typically more severe than male poverty." It stated further that women "suffer violence by men on a large scale. They are more likely to be illiterate as well as 
An Assessment of Rural Poverty and Food Insecurity in Fika Local Government Area, Yobe State, Nigeria

politically and socially excluded in their Communities. Hence, abilities of women to overcome poverty are generally different from those of men.

There is also gender related 'time poverty'. According to OECD (2000:32), this refers to the lack of time for all the tasks imposed on women, for rest and for economic, social and political activities. It is an important additional burden, which in many societies is due to structural gender inequality, a disparity that has different meanings for women and men.

It is necessary to view poverty from an all-inclusive perception to enable adequate and effective ways to be formulated and implemented. World Bank Report of 1990 adopted a view of poverty that covered various aspects of deprivation as "encompassing not only material deprivation (measured by an appropriate concept of income or consumption) but also low achievements in education and health."

The Central Bank of Nigeria (1999:1) views poverty as

a state where an individual is not able to cater adequately for his or her basic needs of food, clothing and shelter; is unable to meet social and economic obligations; lacks gainful employment, skills, assets and self-esteem; and has limited access to social and economic Infrastructure such as education, health, portable water, and sanitation; and consequently, has limited chance of advancing his or her welfare to the limit of his or her capabilities.

The World Bank (2000) utilized inductive approach to uncover dimension of poverty and therefore defined poverty using many indices. One of such definitions is that poverty is "the lack of what is necessary for material well-being especially food, but also housing, land, and other assets. In other words, poverty is the lack of multiple resources that leads to hunger and physical deprivation." There is also the non-material dimension to poverty, which is manifested in incapacities to participate fully in the political and socio cultural activities of one's community. Simply put, poverty is physical weakness, vulnerability; powerlessness and isolation as captured by the deprivation trap (Chambers, 1983).

\subsection{Meaning and Conceptual Issues of Food Security/Insecurity}

Food security is a concept that has evolved during the 1990s far beyond a traditional focus on the supply of food at the national level. This concept has been given general definitions in the time past but in recent times, there has been a divergence of ideas on what food security really means. According to World Bank (1986), food security was defined as access by all people at all times to enough food for an active and healthy life. The committee on world food security defined it as physical and economic access to adequate food by all household members without undue risk of losing the access. However, the definition adopted by the countries attending the world food summit of 1996, and reconfirmed in 2002, accepts the USAID'S concept which has three key elements viz; food availability, food access and food utilization. However, a fourth concept is increasingly becoming accepted that is "the risks that can disrupt anyone of the first three factors"

There are therefore, four major elements of food security. They are food availability, food access, food utilization and not losing such access. Availability, access and utilization are hierarchical in nature. Food availability is necessary but not sufficient for food accessibility and access is necessary but not sufficient for utilization. In a larger sense, two broad groups of factors determine food security. These are supply side factors and demand side factors. The supply-side factors are those that determine food supply or food availability, in other words, they are determinants of physical access to food at national, household and intra-household levels. The demand side factors on the other hand are factors that determine the degree of access of countries, households and individuals to available food. They are, in other words, determinants of economic access to food or determinants of entitlement to available food. Common to these two sets of factors however is another set of factors that affect the stability of both physical and economic access to foods.

Food insecurity or lack of access to nutritionally adequate diet in a household or country can take various forms. For example, chronic food insecurity exists when food supplies are persistently insufficient to supply adequate nutrient for all individuals. Transitory food insecurity occurs when there is a temporary decline in access to adequate food because of instability in food production, food price increases or income shortfalls. 
An Assessment of Rural Poverty and Food Insecurity in Fika Local Government Area, Yobe State, Nigeria

We may distinguish between national food security and household food security. This distinction is necessary because an aggregate supply of food, from domestic sources or import or both are prerequisite but certainly not a sufficient condition for a food secure situation in a country. In other words, adequate availability of food in Nigeria on a per capita basis does not necessarily translate to sufficient and adequate food for every citizen. Food security at household level is a subset of the national level and it requires that all individuals and households have access to sufficient food either by producing it themselves or by generating sufficient, income to demand for it.

Food availability is a function of the combination of domestic food stocks; commercial food imports, food aid, and domestic food production, as well as the underlying determinants each of these factors. Use of the term availability is often confusing since it can refer to food supplies available at both household level and at a more aggregate (regional and national) level. However, the term is applied most commonly in reference to food supplies at a regional or national level.

Food access is influenced by the aggregate availability of food through the impact of the latter on supplies in the market and therefore, on market prices. Again, some suggest that access is further determined by the ability of households to obtain food from their own production and stocks, from the market and from other sources. These factors are in turn determined by the resource endowment of the household, which defines the set of productive activities they can pursue in meeting their income and food security objectives.

Food utilization, which is typically reflected in the nutritional status of an individual, is determined by the quantity and quality of dietary intake, general childcare and feeding practices, along with health status and its determinants. Poor infant care and feeding practices, inadequate access to, or the poor quality of, health services are also major determinants of poor health and nutrition. While important for its own sake as it directly influences, human wellbeing, improved food utilization also has feedback effects, through its impact on the health and nutrition of household members, and therefore, on labour productivity and income earning potential.

Food security may have different meaning for different people. Many definitions have been offered for food security in the literatures. According to Siamwalla and Valdes (1994) food security is the ability of countries regions or households to meet targeted level of food consumption on a yearly basis. The international conference on Nutrition (ICN) held in Rome (1992), defined food security as "access by all people at all times to the food needed for a healthy life". FAO (1992).

According to Gurkan (1995:31-33), "food security is a state of affairs where all people at all times have access to safe and nutritious food to maintain a health and active life". Various schools of thoughts have attributed food security problems to different things including distribution, storage and marketing. Further, some believe that the Nigerian food security problem is the product of Structural Adjustment Programme (SAP, 1985), which simultaneously made food exports very attractive; through raising phenomenally the cost of producing food. Some observers believe that food security problems are as a result of over dependence on the small-scale farmers. According to this view, the large-scale mechanized farmers like that of American should replace the small-scale farmers in Nigeria. Others believe however, that small-scale farmers have not done badly, even though they are illiterates, but behave rationally to economic incentives. Also, a school of thought believes that public policy on food and agriculture is itself at the root of Nigerian food security problems. According to this school, food policy has been characterized by inappropriate role of government in food and Agriculture, which manifest in badly formulated and poor executed food ways and the perennial emergence of the unintended consequences and beneficiaries of the food and agricultural ways.

According to Sharma (1992), national food availability is determined mainly by domestic net of supply and food importation. The capacity to import food in turn depends on export earnings, foreign exchange reserves, and value of essential non-food import and debt service obligations. There is almost no end to the identified factors, which affect food security status of a nation. But in the final analysis, it can be generalized that factors associated with socio-economic development are also those that influence national food security status.

On the other hand, Siamwalla and Valdes (1994) argued that, Food insecurity is generally accounted within fluctuations in household own-food production and food prices. Also, Idachaba (1989) Indicated that food price inflation constitutes the greatest threat to the living standard of Nigerians. 
An Assessment of Rural Poverty and Food Insecurity in Fika Local Government Area, Yobe State, Nigeria

Bashir (1986) mentioned that, the factors contributing to food problems in Nigeria varies from manmade problems to natural forces. (Gurka (1995) has aptly demonstrated the complexity of food security matrix by pointing out that food security is consistently not only linked with food production but also general economic and social development variables. But to improve the food production element of the food security matrix alone requires consistent improvement in yield and labour productivity, an improvement which in turn requires improvement in socio-economic infrastructures in Agriculture, upgrading the quality of human resource-instituting virile Agricultural research and extension system and providing price and non-price incentives for the adoption of new technology.

Most of the origins of food insecurity have an element of economic access to food, directly or indirectly. Economic access is not limited to monetary access; it includes access to land, to credit, to education and to health services that food security is more a problem of whether or not food can be accessed. (Per, 1994) showed from his studies clearly that food insecure people are usually not able to meet their needs from the market.

Nigeria's per capita income has been declining progressively, making Nigerians not to have economic access to food on continuous basis. Progressive increase in population from 88.9 million in 1991 to 103.3 million in 1996 and probably now to about 170 million without corresponding increases in food output seem to have worsened the food security situation generally in Nigeria and the rural areas such as Fika Local Government Area in particular.

As World Bank (1991) has noted, there is normally an overlap between poverty and food security due to inadequate income and wealth and hence, their inadequate access to available food. In addition, income growth, however, helps improve food demand and hence, food security. Food demand and supply trends are known to influence prices as well as the composition in their diets and other factors related to food security. Although food insecurity is usually associated with rural households and urban poor who are more vulnerable to high food price and limited access to food as a result of low income, there are differences between household food security within the urban and rural areas. While real wage and employment are the main determinants of food security in the urban areas, the level of domestic food production dictated by the extent and ease of access to production inputs and services is a primary determinant of food security in rural areas (Omonona et-al, 2007).

\subsection{Theoretical Framework: Cyclical Theory of Poverty}

This theory has its origins in economics in the work of Myrdal (1957:23) who developed a theory of "interlocking, circular, interdependence within a process of cumulative causation" that helps explain economic underdevelopment and development. Myrdal notes that personal and community wellbeing are closely linked in a cascade of negative consequences, and that closure of a factory or source of employment can lead to a cascade of personal and community problems including migration of people from a community. Thus, the interdependence of factors creating poverty actually accelerates once a cycle of decline is started. The cyclical explanation explicitly looks at individual situations and community resources as mutually dependent, with uncertain economy, for example, creating individuals who lack resources to participate in the economy, which makes economic survival even harder for the community poverty has come to stay since people have little or no contribution they offered.

There exist a number of scholars who advocated the cyclical theory but for the purpose of this study emphasis will be on Oswald Spangler and his life cycle of culture model. This theory premises its assumptions on the word 'cycle' in its attempt to explain any social phenomenon. Cyclical theory has the following assumptions:

- that every human society passes through a continuous pattern or cycle

- That these continuous cycles pass through growth and decay and resume the cycle.

- That the progress of culture through history passes through a definite stage and leads back to the origin of that culture with the passage of time.

- That change in any society lends back to the start.

Spangler in his work "The Decline of the West" argued that, the prime phenomenon (culture) is the collection of past and future world history. These assumptions explain the culture of rural poverty, 
An Assessment of Rural Poverty and Food Insecurity in Fika Local Government Area, Yobe State, Nigeria

arguing that a poor society is poor and will remain poor because they are poor (korotayev, A. et al, 2006). This analysis is evident in the vicious circle of poverty. That the poor has low disposable income and as a result of this has low investment which leads to low profit and low profit leads to low savings and low savings leads to low output which eventually leads back to poverty.

\section{Methodology}

\subsection{Population of the Study}

The population of this study involved all the heads of households in Fika Local Government Area. This category was selected as the sample respondents because they could provide the required information for the research. Household heads were chosen because they are the breadwinners, and they control the means of production and organise the production activities.

\subsection{Sample Size/ Sampling Technique}

However, considering the large size of Fika Local Government Area, it is not easy for the researcher to cover all the household heads of the area, hence, the need to take a specific sample. In this regard, a total of 300 respondents were selected to serve as the sample size of the study. In addition, 10 key informants, comprising the head of the Department of Agriculture, Fika Local Government Council; three extension workers; 6 leaders of farmers (Sarkin Noma) or opinion leaders, were selected.

In this work, multi-stage cluster sampling technique was used in selecting the respondents for the administration of questionnaires. The technique is used frequently when the sampling frame does not exist.

Fika Local Government Area was divided into two clusters- Fika East and Fika West. Each part has five political wards, from which the researcher selected three from each, making a total of six wards. One village each from the six political wards selected were chosen using lottery method. The names of the villages were written on pieces of papers, which were folded and put in a container. They were consequently shaken and thrown away. Six were picked and the names of the villages on the six pieces of papers were considered. The researcher accidentally selected a sample of 50 houses from each of the 6 villages, which gave a total of 300. From each of the houses selected the head of the household was chosen.

The head of these households were interviewed by the research assistants; who were undergraduate students, they were trained on how to go about the data collection and they have the ability to translate the questionnaires to the understanding of the respondents without tempering with the actual message the questions contained. For the KII respondents, the researcher selected the Director of Agriculture of Fika LGA, together with three Agricultural Extension Workers in the LGA. The researcher also interviewed one farmers' leader (Sarkin Noma) in each of the villages that were selected which give us a total of six respondents and in cases where the leaders are not available, opinion leaders were used in the KII, hence for the KII there is a total of 10 respondents who were interviewed on face to face. The villages selected from Fika east are Dumbulwa, Duffoyel, and Janga while on the western part of the local government the villages of Garin-Gamji, Fusami and Garin Aba were selected. The sampling technique is necessary because it is difficult to have an exhaustive list of the entire population per unit.

\section{DISCUSSION OF MAJOR FINDINGS}

Table1.1. Respondents' access to basic needs

\begin{tabular}{|l|l|l|}
\hline \multicolumn{1}{|c|}{ Number of meals per day } & \multicolumn{1}{c|}{ Frequency } & \multicolumn{1}{c|}{ Percentage (\%) } \\
\hline One time & 9 & 3.4 \\
\hline Two times & 204 & 77.6 \\
\hline Three times & 50 & 19.0 \\
\hline Total Access to health care & $263 \quad$ Frequency & 100.0 \\
\hline \multicolumn{1}{|c|}{ Percentage } \\
\hline Accessible & $59 \quad 204$ & 22.4 \\
\hline Not accessible & 263 & 100.0 \\
\hline Total & \multicolumn{2}{|c|}{} \\
\hline
\end{tabular}


An Assessment of Rural Poverty and Food Insecurity in Fika Local Government Area, Yobe State, Nigeria

\begin{tabular}{|l|l|l|}
\hline \multicolumn{1}{|c|}{ Access to clean water } & \multicolumn{2}{c|}{ Frequency } \\
\hline Accessible & 49 & 18.6 \\
\hline Not accessible & 214 & 81.4 \\
\hline Total Access to descent shelter & $263 \quad$ Frequency & 100.0 \\
\hline \multicolumn{1}{|c|}{ Percentage (\%) } \\
\hline Accessible & $51 \quad 19.4$ \\
\hline Not accessible & 212 & 80.6 \\
\hline Total & 263 & 100.0 \\
\hline
\end{tabular}

Source: Field Survey, 2014

Table 1.1 above evaluated the respondents' access to basic needs. It shows that only $19.0 \%$ of the respondents eat three meals daily. The qualitative data collected through key informant interview confirms the above findings that most of the people in the area eat at least two times per day.

According to one respondent:

We here, most of us eat at least two times in a day; we mostly eat the previous day's remnant (dumame) in the morning; we only drink pap in the afternoon and eat tuwo in the night ... Sometimes, we eat kamzo in place of the pap (Sarkin Noma, Dumbulwa).

Similarly, another respondent revealed that:

As for me, I eat three times in a day but most people eat only two times because they cannot afford three square meals (Opinion leader, Janga)

Another respondent stated that:

Majority of us eat two times in a day ... we are only managing; only rich people can afford three square meals in this village (Sarkin Noma, Janga).

On access to clean water, $214(81.4 \%)$ of the respondents said they lacked access to portable clean water, while $49(18.6 \%)$ said they could easily access clean water. This implies that most residents of Fika Local Government Area lack portable clean water and are, therefore, prone to water borne diseases such as dysentery and cholera that could be contacted from taking dirty water.

Table 1.1 also shows that $51(19.4 \%)$ of the respondents said they had access to decent shelters, while $212(80.6 \%)$ said they did not. This shows that majority of the respondents, and, by extension, the inhabitants of Fika Local Government Area, do not have access to decent shelter. This implies that most of them are poor and cannot afford to rent or build modern houses. The three indices clearly portray the level of paucity of basic needs of the people which indicate the lack of capacity to deal or tackle problems relating to their feeding, health and education. The result of the key informant interview also shows that the basic needs of life are lacking in the areas of Fika LGA

A respondent opined that:

We in Garin Gamji do not have any health centre; a person has to go to Gadaka when sick ... Our source of water is very poor; we have a primary school but it lacks enough teachers; in terms of decent shelter, we are only managing because, as you can see, we are living in mud houses with thatched roofing (Opinion leader, Garin-Gamji).

Another respondent stressed that:

Here in Dumbulwa, we don't have a health centre but we have good drinking water ... We have a primary school but it lacks teachers. However, educated boys in the village do volunteer to teach the children (opinion leader, Dumbulwa)

Table1.2. Reasons for the sale of farm produce

\begin{tabular}{|l|l|l|}
\hline \multicolumn{1}{|c|}{ I produce excess } & \multicolumn{1}{c|}{ Frequency } & \multicolumn{1}{c|}{ Percentage (\%) } \\
\hline Yes & $58 \quad 42.6$ \\
\hline No & 78 & 57.4 \\
\hline Total Lack of storage facilities & $136 \quad$ Frequency & 100.0 \\
\hline \multicolumn{1}{|c|}{ Percentage (\%) } \\
\hline Yes & $19 \quad 14.0$ \\
\hline No & 117 & 86.0 \\
\hline Total & 136 & 100.0 \\
\hline
\end{tabular}


An Assessment of Rural Poverty and Food Insecurity in Fika Local Government Area, Yobe State, Nigeria

\begin{tabular}{|l|l|l|}
\hline \multicolumn{2}{|c|}{ To meet Family's daily needs } & \multicolumn{2}{c|}{ Frequency } & \multicolumn{2}{c|}{ Percentage (\%) } \\
\hline Yes & 97 & 71.3 \\
\hline No & 39 & 28.7 \\
\hline Total To meet Special needs & $136 \quad$ Frequency & 100.0 \\
\hline \multicolumn{1}{|c|}{ Percentage (\%) } \\
\hline Yes $127 \quad 09$ & 93.4 \\
\hline No & 136 & 6.6 \\
\hline Total & 136 & 100.0 \\
\hline
\end{tabular}

Source: Field Survey, 2014

Table 1.2 above shows the reasons given by the respondents for the sale of their farm produce some respondents said they produced in excess, $71.3 \%$ said they sold their farm produce to meet their daily needs, while $93.4 \%$ said they sales to solve their special needs. It is evident from the table that storage is not a major problem in making the farmer sell their produce. The most compelling reason for sale of produce is that of special needs, followed by the need to meet various family requirements. Given the fact that most of the farmers hardly provide excess and even those who do the surplus is not large enough to allow for adequacy of the food for all year round.

Table1.3. Respondents' views on the factors responsible for food shortage in Fika Local Government Area

\begin{tabular}{|c|c|c|}
\hline Low income & Frequency & Percentage (\%) \\
\hline Yes & 165 & 62.7 \\
\hline No & 98 & 37.3 \\
\hline Total & 263 & 100.0 \\
\hline Low production & Frequency & Percentage (\%) \\
\hline Yes & 66197 & 74.9 \\
\hline No & 19766 & 25.1 \\
\hline Total & 263 & 100.0 \\
\hline Selling of food items when cheap & Frequency & Percentage $(\%)$ \\
\hline Yes & 206 & 78.3 \\
\hline No & 57 & 21.7 \\
\hline Total & 263 & 100.0 \\
\hline Poor storage facilities & Frequency & Percentage $(\%)$ \\
\hline Yes & 181 & 68.8 \\
\hline No & 82 & 31.2 \\
\hline Total & 263 & 100.0 \\
\hline
\end{tabular}

Source: Field Survey, 2014

Food security is very important as any individual, family, community, or nation that is assured of its food supplies, will have time for other developmental activities. The responses express by the people in table 1.3 shows that these are all valid reasons for the food shortages experienced in Fika Local Government Area. Thus, government through its various agencies should come up with ways to reduce the problem of food shortage in Fika Local Government Area and the country in general.

Similar responses were received from the farmers' leaders. Commenting on the factors responsible for food shortage in the rural areas of the local government area, the discussants enumerated the factors to include lack of farming equipment, poverty, lack of storage facilities and natural disasters factors such as flood, drought, insect and pest attacks, among others. One of the discussants explained that:

Of course, there are many factors that contribute to food shortage. They include poverty because, if you are poor, you cannot buy farming tools. Other factors include drought and flood. In addition, there are other people that sell out their produce which also leads to food shortage for the family and in the area (Opinion leader, Janga).

Similarly, another discussant adds that:

Yes, we have the problem of poverty and migration of the youth to the city which leads to food shortage. Sometimes, we get attacks on our farmlands by insects and pests and we also experience flood, which all contribute to food shortage (Sarkin Noma, Kerem).

On the side of the agricultural extension workers, one of them revealed that: 
An Assessment of Rural Poverty and Food Insecurity in Fika Local Government Area, Yobe State, Nigeria

There are many factors that lead to food shortage in the rural areas of this local government area. The factors include poverty of the farmers, selling of the farm produce by the farmers, especially during the harvest season when the foodstuffs are cheap. Sometimes, we also experience natural disasters like drought, floods and attacks from insects and pests. These issues really lead to food shortage.

The Director of Agriculture in the local government area similarly revealed that:

You see, many of our farmers sell their farm produce to meet other needs. This is a big problem. Also, we usually face some disasters like flood and drought and also attacks from pests and insects (Director of Agriculture, Fika LGA).

Table1.4. Respondents' views on the factors responsible for persistent poverty in Fika Local Government Area

\begin{tabular}{|c|c|c|}
\hline Rural urban migration & Frequency & Percentage $(\%)$ \\
\hline Yes & 189 & 71.9 \\
\hline No & 74 & 28.1 \\
\hline Total & 263 & 100.0 \\
\hline Lack of farming inputs e.g. fertiliser & Frequency & Percentage (\%) \\
\hline Yes & 181 & 68.8 \\
\hline No & 82 & 31.2 \\
\hline Total & 263 & 100.0 \\
\hline Lack of rural extension officers & Frequency & Percentage (\%) \\
\hline Yes & 79 & 30.0 \\
\hline No & 184 & 70.0 \\
\hline Total & 263 & 100.0 \\
\hline Natural factors & Frequency & Percentage (\%) \\
\hline Yes & 166 & 63.1 \\
\hline No & 97 & 36.9 \\
\hline Total & 263 & 100.0 \\
\hline
\end{tabular}

Source: Field Survey, 2014

Table 1.4 shows respondents' views on the factors responsible for persistent poverty in Fika Local Government Area. The factors where respondents view are sought include rural urban migration, lack of farming inputs, lack of rural extension officers and natural factors example drought, all this factors positively contribute to poverty situation of the rural dwellers as results of the study shows.

Table1.5. Respondents suggestions on the way to address the problem of food insecurity and poverty in Fika Local Government Area

\begin{tabular}{|c|c|c|}
\hline Government Intervention & Frequency & Percentage $(\%)$ \\
\hline Yes & 253 & 96.2 \\
\hline No & 10 & 3.8 \\
\hline Total & 263 & 100.0 \\
\hline Empowerment of Rural Farmers & Frequency & Percentage (\%) \\
\hline Yes & 256 & 97.3 \\
\hline No & 07 & 2.7 \\
\hline Total & 263 & 100.0 \\
\hline Public Private Partnership & Frequency & Percentage (\%) \\
\hline Yes & 157 & 59.7 \\
\hline No & 106 & 40.3 \\
\hline Total & 263 & 100.0 \\
\hline Increased Education & Frequency & Percentage (\%) \\
\hline Yes & 220 & 83.7 \\
\hline No & 43 & 16.3 \\
\hline Total & 263 & 100.0 \\
\hline
\end{tabular}

Source: Field Survey, 2014

Table 1.5 shows the responses of respondents as the ways they suggested in addressing problems of poverty and food insecurity in Fika Local Government Area. The respondents views have so many support of the recent studies and also agreed with CBN position on poverty reduction ways. This 
An Assessment of Rural Poverty and Food Insecurity in Fika Local Government Area, Yobe State, Nigeria

implies that majority of the respondents, want to be trained and empowered by government and NGOs to increase their capacity to provide food thereby solving the problem of food shortage and insecurity in Fika Local Government Area.

From the part of the respondents that were interviewed, they suggested ways that could be adopted to address the problem of food shortage and food insecurity to include increased intervention and attention on the part of the government, supply of farming needs, alleviation of poverty and abstaining from the sale of farm produce, especially immediately after harvest. A respondent suggested that:

If government can have the political will, I believe it can alleviate our sufferings. Also, our people need to be enlightened about the dangers of selling their farm produce. There is also the need for the government to supply farmers with enough fertiliser and farming equipments (opinion leader, Dumbulwa).

Similarly, from another location, a respondent says that:

We want government and NGOs to help us with fertiliser and other farming needs such as enhanced seeds (Opinion leader, Garin-Gamji).

An agricultural extension worker in the local government area also reveals that:

There is the need for government to intensify its efforts in helping rural farmers with soft loans to purchase some farming needs. There is also the need for government to supply the farmers with enough fertiliser. The farmers should also avoid selling their meagre foodstuffs, especially when they are cheap (Agricultural extension worker, Fika Local Government Area)

Similarly, the Director of Agriculture of Fika Local Government Area also suggested thus:

There is need for the people to imbibe the act of farming and the farmers should try and adequately store their farm produce and avoid selling them. Government should also devote more resources to the agricultural sector (Director of Agriculture, Fika LGA)

\section{CONCLUSION}

Poverty and food insecurity in is a serious challenge which requires the attention of government, NGOs' as well as community leaders in order to help people out of its negative effect. Provision of required farm implements and improve seeds as well as extension workers would serve as succor for farmers in rural areas to improve their production capacity which will give them surplus to make other needs meet. NGOs' can also render vital assistance in the life of rural farmers either as donors or supporting actors through awareness and sensitization on food security strategy.

\section{REFERENCES}

[1] Bashir, W (1996) Food Crisis and Government Response in Nigeria: Critique of the River Basin Development Authority. Boston: African Studies Centre.

[2] Central Bank of Nigeria /World (1999) BANK: Nigeria's Development Prospects: Poverty Assessment and Alleviation Study Central Bank of Nigeria in Collaboration with the World Bank, Washington D. C.

[3] Chambers R. (1983) "Integrated Rural Poverty" in Rural Development Putting the Last First. Produce through Longman publishers Malaysia pp

[4] Federal Office of Statistics (1992) "world food outlook" FAO Rome.

[5] Gurkan A.A (1995) The mathematics of hunger CERES 27(2): 31-33.

[6] Idachaba F.S (1989) "The Nature of Nigeria Food Problem" paper presented at National Symposium on Nigerian Food Question, Organized by College of Agricultural Economics and Extension. University of Agriculture Makurdi, Nigeria.

[7] Korotayev, A., et al, (2006) Introduction to Social Macro dynamics: Secular Cycles and Millennial Trends. Moscow: USSR

[8] New Nigeria News Paper, March 7, 1990.

[9] Narayan, D. et al (2000) Voices of the Poor: Can Anyone Hear Us? World Bank, New York.

[10] Myrdal, G. (1957) Economic Theory and Underdeveloped Regions London: Gerald Duckworth and Co.

[11] Organisation for Economic Cooperation and Development (O.E.C.D). (2000:29) Guidelines on Poverty Reduction. 
An Assessment of Rural Poverty and Food Insecurity in Fika Local Government Area, Yobe State, Nigeria

[12] Oyemomi, E. O. (2003) "Poverty Eradication of the Federal Government: Roles of States, Local Governments and NGOs." A paper presented at National Workshop on International Currency Reform and Economic Management for Sustaining Profitability Under 2003 Monetary Policy for Sustainable Development at Merit House Abuja.

[13] Patel, S. (1994) “Social Indicators for Development” Finance and Development.

[14] Per, P. A. (1994): food security and nutrition monitoring IFPRI Washington D.C.

[15] Sanni L. O. (2000): Agricultural Development without Post Harvest System: Any Hope for Success? University of Agriculture, Abeokuta Alumni Association Lecture Series No. 2. 23P.

[16] Siamwalla A and Valdes A. (1994) Food Security in Developing Countries; International issues. IFPRI Was

[17] Tollens, F. (2000) Food Security: Incidence and Causes of Food Insecurity Among Vulnerable Groups and Coping Strategies, In. CTA (2000) Food Insecurity in ACP Countries, Proceedings of a CTA Seminars, pp 27-50.

[18] Sharma R.P (1992): Monitoring Access to Food and Household Security: Food Nutrition and Agriculture 2(4).

[19] World Bank (1999) "Nigerian Consultations with the Poor".Report of the Global Synthesis Workshop Septmember 22-23, 1999.

[20] World Bank (1986) Poverty and Hunger, Issues and Options for Food Security in Developing Countries. A World Bank policy study Washington, D.C

[21] World Bank (1991) Nigeria strategy for food and nutrition security. World Bank Document Report no 9040-uni

\section{AUTHORS' BIOGRAPHY}

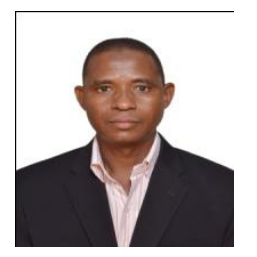

Suleiman Kawuwa is a lecturer with Sociology Department Yobe State University Damaturu; holds M.Sc. Sociology from Bayero University Kano, B. Sc Sociology and Anthropology University of Maiduguri and currently $\mathrm{PhD}$ scholar at Centre for Policy Research and International Studies, University Sains Malaysia (USM).

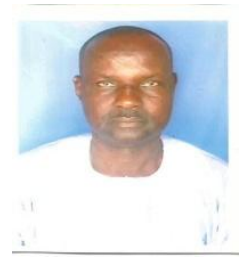

Umar Lawal Yusuf, lecturer with Sociology and Anthropology Department University of Maiduguri; holds M.Sc. Criminology (2015) from University of Jos, Masters in Industrial and Labour Relations (2009) and B.Sc. Sociology and Anthropology (2003) from University of Maiduguri, currently undergoing $\mathrm{PhD}$ programme in Cultural Sustainability at University of Maiduguri, Nigeria.

Citation: Suleiman Kawuwa, Umar Lawal Yusuf. "An Assessment of Rural Poverty and Food Insecurity in Fika Local Government Area, Yobe State, Nigeria" International Journal of Humanities Social Sciences and Education (IJHSSE), vol 6, no. 1, 2018, pp. 5-17. doi: http://dx.doi.org/10.20431/2349-0381.0601002.

Copyright: () 2019 Authors. This is an open-access article distributed under the terms of the Creative Commons Attribution License, which permits unrestricted use, distribution, and reproduction in any medium, provided the original author and source are credited. 